Anna Franca Plastina*

\title{
Changing discourses of climate change: building social-ecological resilience cross- culturally
}

https://doi.org/10.1515/text-2020-0078

Received May 8, 2020; accepted January 11, 2022; published online January 31, 2022

Abstract: Social-ecological resilience (SER) is setting a new trend of thinking about environmental issues since it considers climate unpredictability as the norm in the Anthropocene and climate disturbance as offering opportunities for change. This paper argues that SER can be conceptualized as a function of narrative text and talk in the recent practice of online environmental activism. Based on a case study, the investigation explores a TED talk by the US environmentalist, Al Gore, and a web-based text by the Indian activist, Vandana Shiva, seeking how meanings of climate change enhance resilience building. A mixed-method research design is used to perform a discursive frame analysis on the sample discourses, guided by key resilience-building principles, and framed by the methods of critical discourse and frame analyses. The twofold aim is to analyse how micro-linguistic features mediate social-ecological memory and novelty as key SER drivers, and how macro-discursive frames are selected to shape meanings cross-culturally. Based on these findings, the comparative analysis at the socio-discursive level highlights how SER ideologies underpinning these discourses particularly diverge in the context of the Global North/Global South divide. Overall, the study findings shed light on the multiple meanings of SER shaping more constructive responses to climate change.

Keywords: climate change; cross-cultural meanings; discursive frame analysis; resilience discourse; social-ecological resilience (SER)

\section{Introduction}

Social-ecological resilience (SER) has been gradually gaining ground ever since major attention was drawn to "the integrated concept of humans-in-nature"

\footnotetext{
*Corresponding author: Anna Franca Plastina, Department of Pharmacy, Health and Nutritional Sciences, University of Calabria, Via P. Bucci - 87036 Rende, Cosenza, Italy,

E-mail: annafranca.plastina@unical.it
} 
(Berkes and Folke 1998: 4). SER refers to "the capacity to adapt or transform in the face of change in social-ecological systems, particularly unexpected change, in ways that continue to support human well-being" (Folke et al. 2016, socialecological systems and resilience section, para. 1). It thus assumes that climate "unpredictability is the new norm" (Dalby 2013: 41) and that its "disturbance can trigger positive change” (Folke et al. 2003: 376; added emphasis).

Against this backdrop, this paper argues that SER discourse deserves noteworthy attention for its more positive outlook compared to anthropocentric discourses, and positions itself in response to the plea for further investigation on the evolution of climate change communication (cf. Fleming et al. 2014; Fløttum 2014). Hence, there is a timely need to investigate newly emerging discourses which translate resilience from buzzword to action in a compelling manner to enhance public engagement. As a case in point, the study reported here explores SER discourses emerging from the Internet-based phenomenon of "online activism" (McCaughey and Ayers 2003), which is meant to strengthen offline grassroots environmental activism. Unlike other traditional media discourses which strive to achieve the "newsworthiness" of climate disturbance (Weingart et al. 2000), online grassroots discourse generally aims at boosting collective resilience to climate change.

In particular, the study analyses the linguistic features and discourse frames embedded in the online SER-building discourses of the Indian activist Vandana Shiva and the US environmentalist Al Gore. From a cross-cultural perspective, it is further argued that these environmental activists, as representatives of the Global North and the Global South, are likely to frame their discourses under the influence of their local context, regardless of the global reach of their online activism. The cross-cultural approach taken seems also to respond to the current ecolinguistic demand to expand discourse studies on climate change beyond the Anglo-American sphere (Penz 2018).

The following research questions guide this study:

1. Which linguistic features mediate "ecological and social memory" and "novelty" to enhance resilience building?

2. Which discourse frames are cross-culturally selected to boost public engagement in resilience building?

This paper is organized as follows. Literature review is presented in Section 2 along the following issues: the principles of building social-ecological resilience considered in the study (Section 2.1), and the features of SER discourse (Section 2.2). Data and method are presented in Section 3 describing the corpus of data (Section 3.1), the method (Section 3.2), and analytical procedure (Section 3.3). In Section 4, a detailed discursive frame analysis is presented, respectively, at the 
micro-linguistic, macro-structural ${ }^{1}$ and socio-discursive levels (Sections 4.1-4.3). Finally, Section 5 provides a discussion of the key findings and concludes with some remarks on SER discourse.

\section{Literature review}

\subsection{Building social-ecological resilience: principles}

SER seems to reflect the societal significance of the Anthropocene since it urges thinking about the future in a more constructive manner based on the premise that human action has possibly become "the most important driver of ecological change” (Benson and Craig 2017: 4; original emphasis). SER thereby marks a paradigm shift away from the anthropocentric way of thinking about the environment. Unlike the twentieth-century 'command and control' approach, which claimed that "the uncertainty of nature" can be easily replaced with the human “certainty of control" (Gunderson 2000: 433), SER privileges human-nature interdependency. Rather than considering that "humans are separate from nature" and that "nature is 'ours' to use" (Benson 2015: 109; original emphasis), SER contemplates adaptation and transformation as potentially positive opportunities to cope with environmental vulnerability. According to the Intergovernmental Panel on Climate Change (IPCC), adaptation is, in fact, understood as "the adjustment in natural or human systems in response to actual or expected climatic stimuli or their effects, which moderates harm or exploits beneficial opportunities" (IPCC 2007: 6; added emphasis). It is therefore closely connected to the urge to build resilience (Cannon and Müller-Mahn 2010) as a crucial step in "transforming our world" (cf. the United Nations 2030 Agenda for Sustainable Development). ${ }^{2}$

Nevertheless, SER is still very much in its infancy. So far, there is, in fact, "little agreement on how adaptation or resilience is built, analysed, and applied in practice" (Borquez et al. 2017: 164). This is mainly due to the complex nature of managing resilience in the face of the innumerable environmental issues in the Anthropocene. As a result, "there does not yet exist a definitive set of resilienceenhancing principles” (Biggs et al. 2012: 424).

1 The macro-structural level refers to the use of frames as "macrostructures [which] are higherlevel semantic or conceptual structures that organize the 'local' microstructures of discourse, interaction, and their cognitive processing" (van Dijk 1980: v).

2 The Agenda (https://sustainabledevelopment.un.org/post2015/transformingourworld) was adopted by all UN member states in 2015. 
Nonetheless, Folke et al. (2003: 383) identify four basic principles of building SER which are considered in this study. These are summarized as follows:

- Principle 1: "learning to live with change and uncertainty" refers to "evoking disturbance" and "expecting the unexpected". It thus implies moving between past and hypothetical future events as a constant adjustment to the change and uncertainty inherent in climate variation. Accordingly, adjustment is here accomplished by learning from previous natural disaster events.

- Principle 2: "nurturing diversity for reorganization and renewal" encompasses "social-ecological memory", which is enhanced by combining "ecological memory", or "the life-history experience with environmental fluctuations" with "social memory", or "the long-term communal understanding of the dynamics of environmental change and the transmission of the pertinent experience" (Folke et al. 2003: 20). Memory is therefore crucial for reorganization and renewal since it acts as the bridge between the past and the future.

- Principle 3: “combining different types of knowledge for learning” highlights the need for both "experiential and experimental knowledge", besides "fostering complementarity of different knowledge systems” (Folke et al. 2003: 383), including local and traditional ones. Hence, knowledge is the fundamental source for "learning to live with change and uncertainty" (Principle 1) and for "reorganization and renewal" (Principle 2).

- Principle 4: "creating opportunity for self-organization" stresses the capacity "to continually self-organize and adapt in the face of ongoing change" (Folke 2016, capturing resilience section, para. 1). Self-organization thus encapsulates the other three principles as it is grounded in learning, social-ecological memory and knowledge, besides presupposing action-oriented plans calling for active agency.

In one way or another, these principles appear to reflect "the dynamic balance between change and memory" (Berkes et al. 2003: 19). Memory is therefore "a key component of resilience" as it evokes past disturbances and thereby "open[s] up space for change" (Folke et al. 2003: 376). It, in fact, provides "context and sources for renewal, recombination, innovation, novelty and self-organization following disturbance" (Folke 2006: 259).

Moreover, memory as a social construct is strictly related to the use of language to represent the past (Linde 2015), and thereby relies on "narrative templates" (Wertsch 2008), also to shape SER discourse.

\subsection{SER discourse: narratives and frames}

Building resilience presupposes that change is constructed as a "structured account of a possible future" by means of "brief narratives that link historical and 
present events with hypothetical future events" (Peterson et al. 2003: 360-361). O'Brien (2017: 43) adds that "a common way to imagine environmental futurity in the early decades of the twenty-first century is through stories about resilience". Consistently, Basseler (2019:18) notes that "resilience, as a central emerging concept and concern of the twenty-first century, is significantly constructed through narratives". Narratives can be considered a powerful tool in environmental discourse as they better illustrate the tight coupling of human and natural systems (cf. Plastina 2018). As Böhm et al. (2019, climate change narratives section, para. 1) note, "evidence suggests that narratives rather than scientific facts represent people's understanding of climate change", and they are thereby found to encourage action-taking on climate change in all audiences (Morris et al. 2019).

Narratives, however, reflect evolving socio-cultural beliefs about environmental issues and can therefore be grouped into different thematic types. Benson (2015), for instance, makes a distinction between tragedy, sustainability and resilience narratives. The tragedy narrative, developed in the post-World War II period, triggers "command and control" storylines coupled with narratives of fear of scary events, which do not encourage humans to take on environmental challenges at all. The sustainability narrative became influential in the 1970s when major focus was placed on sustainability rather than on ecological problems and fears. With its assumption that we "have the capacity to hold onto some type of stationarity and/or equilibrium" (Benson 2015: 111), this type of narrative does not take the inherent disequilibrium of the environment into account and is thus deemed inappropriate in the Anthropocene.

Conversely, the resilience narrative focuses on “change and on the system's capacity to meaningfully respond to change [...] The emphasis is building adaptive capacity rather than maintaining stationarity" (Benson 2015: 115-116; original emphasis). While the resilience narrative also depicts climate vulnerability, it, however, places greater emphasis on new developmental paths, which thus offer "a new narrative for the Anthropocene" (Benson and Craig 2017: ix).

From the linguistic perspective, narratives are closely related to the construct of discourse frames since "frames are interpretive storylines" (Nisbet 2009: 15). Although frames as mental structures are latent, they can, however, be detected through small, manifest elements in discourse, including "keywords, stock phrases, stereotyped images, sources of information, and sentences that provide thematically reinforcing clusters of facts or judgements" (Entman 1993: 52), as well as key expressions, synonyms, identical words (Entman et al. 2009: 176). These create clusters of framing elements which organize the narrative structure of SER discourse, leading from an initial situation - through a complication, a reaction and a resolution - to a final situation (Fløttum and Gjerstad 2017). Hence, frames can function to promote an interpretation of a problematic situation, support a 
desirable response and to provide an emotional charge (Entman et al. 2009: 176). Framing is found to be particularly effective in climate change communication for public engagement. León et al. (2018: 109), for instance, note that "when it comes to environmental issues, framing can be an important tool to help gather attention [...] and effectively contextualise as well as 'fix' interpretive categories in order to help explain and describe the complex environmental processes of climate change”. Narrating therefore presupposes organizing a selection of cohesive frames, which are mapped onto significant linguistic tokens, thereby creating a coherent interpretive storyline.

Structurally, the process of framing thus implies "select[ing] some aspects of perceived reality and mak[ing] them more salient in the communicating text" so as "to promote a particular problem definition, causal interpretation, moral evaluation and/or treatment recommendation” (Entman 1993: 52).

Following this key principle of "selection and salience", it is possible to identify the most recurrent frames in climate change communication. Shanahan (2007), for example, considers scientific uncertainty, national security, polar bear, money, catastrophe, justice and equity as the six most common frames deployed for public engagement. Hulme (2009: 229) notes that Shanahan's frames reflect different degrees of public engagement. Since the scientific uncertainty frame seems to appeal only to people who are unwilling to change, it does not boost public engagement (also Böhm et al. 2019). It is therefore likely to be easily replaced by the national security frame to inspire action from the same individuals. The polar bear has traditionally been used as an icon to frame the environmental issue of the endangered Arctic, thus increasing engagement with the issue especially among wildlife lovers. The money frame may strike a chord with those concerned with the costs of climate change (e.g. politicians, economists); the catastrophe frame will probably engage a wider audience worried about the problem of a climate change apocalypse, whereas the justice and equity frame is likely to appeal more to audiences with strong moral leanings.

Overall, the discourse practice of building SER is here taken to be basically featured by:

a) the mediation of SER-building principles through different linguistic expressions;

b) a cohesive narrative structure made up of frames which are detectable in various discursive elements, and which offer "a shared understanding of some problematic condition [...] in need of change", articulate "an alternative set of arrangements" and urge the public "to act in concert to affect change" (Benford and Snow 2000: 615). These features guide the selection of the texts used for this case study. 


\section{Data and method}

\subsection{Corpus}

Online searches were performed using the key expressions "climate change communication", "resilience discourse" and "environmental activists". The top hits yielded were filtered for texts responding to the basic features of SER discourse (cf. Section 2.2) under the condition of being authored by activists from the Global North and Global South. As a result, the materials used as the corpus for the study include Vandana Shiva's web-based text on Climate Change: Biodiversity, Agriculture and Climate Change in the Himalaya (2015), ${ }^{3}$ and Al Gore's TED talk The Case for Optimism on Climate Change (2016). ${ }^{4}$ These two collections form a transcribed corpus of 6,346 total words (367 sentences) with Shiva's text amounting to 3,138 words (146 sentences) and Al Gore's talk amounting to 3,208 words (221 sentences). Concerns have been raised about discourse representativeness in small text samples (cf. Stubbs 1997). For present research purposes, it is argued, however, that the "detailed analysis of a small number of discourse samples” (Fairclough 1992: 230), which are sufficiently balanced in word length, is the only way of analysing certain types of discourse, including SER discourse.

\subsection{Method}

Methodologically, it is worth noting that resilience discourses mediated by environmental activists need to be situated within the wider context of social movements from which they draw their origins. It is thus crucial to find the most fitting methodological approach for the analysis of this specific kind of discourse. Accordingly, a mixed methods research design was employed to perform a combined discursive frame analysis, drawing on the principles of the discoursehistorical approach (DHA) in critical discourse analysis (CDA) and those of frame analysis (FA) for a more fine-grained scrutiny. On the one hand, DHA takes particular interest in how the systems of values and beliefs shaping ideologies, such as SER, are socially mediated through linguistic practices, and how ideologies drive power relations by means of language (Reisigl and Wodak 2016). Although this approach values the sociohistorical, problem-oriented nature of discourse, it still seems to neglect the socio-cognitive dimension of discourse like most CDA studies to date (cf. van Dijk 2018). On the other hand, FA examines the

3 Accessible at: www.navdanya.org/climate-change.

4 Accessible at: www.ted.com/talks/al_gore_the_case_for_optimism_on_climate_change. 
ways in which frames, or "schemata of interpretation" of the real world (Goffman 1974: 21) organize the global coherence of discourse since they link its micro and macro-structures by drawing upon the values and beliefs stored in cognitive schemes. While FA can supplement DHA, there has been, however, "little examination of [the] discursive foundations" of frames (Steinberg 1998: 846). DHA therefore seems to be suitable for filling the FA frame-discourse methodological gap as it can explore the linguistic realizations of frames. It is thus argued that this integrated methodology can better cater for a more comprehensive analysis of SER discourse as a practice mediated by the social movement of environmental activism (cf. della Porta 2014), and that these closely related methods have complementary roles to play (cf. Lindekilde 2014).

\subsection{Analytical procedure}

Analyses were performed at the micro-linguistic, macro-structural and sociodiscursive levels. In-depth micro-analysis was carried out to unpack the linguistic features which make a significant contribution to building SER meanings following Folke et al.'s (2003) key principles (cf. Section 2.1). At this level, raw linguistic data were coded according to the following four parameters introduced as independent variables:

1. evaluating change and uncertainty: evaluative markers (e.g. adjectives, adverbs, action verbs, modal verbs) expressing the activist's attitudes towards evolving and unpredictable climate conditions;

2. nurturing diversity: linguistic items connoted with meanings of "bio" or economic diversity (e.g. loss or gain verbs and nouns, spatiotemporal markers);

3. knowledge for learning: linguistic items depicting knowledgeable actors, institutions, different types of knowledge domains and learning (e.g. proper and collective nouns, verbal markers of learning, spatiotemporal markers);

4. opportunities for self-organization: linguistic elements recalling information related to previous reorganizations (social-ecological memory), signalling selforganization and renewal (novelty) (e.g. spatiotemporal markers, place and organizational names, action verbs).

At the macro-structural level, frame analysis was performed following Entman's (1993) principle of "selection and salience", whereby text segments were mapped in terms of strong/weak selection and salience. Text segments organized as highly important meaning were identified as indicators of strong selection and salience, and related linguistic features were coded as discourse frames based on Shanahan's (2007) model. 
At the socio-discursive level, micro- and macro-data findings were sourced to uncover elements of ideology and power underpinning the sample discourses. A comparative analysis of the most salient ideological constructs was subsequently conducted to account for possible cross-cultural variations based on the criterion of context (Global North vs. Global South). Accordingly, discourse participants with attributes of power were detected and their types of power categorized.

\section{Data analysis}

\subsection{Building resilience at the micro level}

Results from the micro-analysis of Shiva's text recorded a total of 219 linguistic tokens related to one of the four key resilience-enhancing principles (Table 1).

Nurturing diversity is found to be the top-ranking principle with 76 linguistic instantiations (34.7\%) rendered mostly as "bio" nouns (e.g. plants, animal, water) (35.5\%) and verbs indicating gain (e.g. offer, provide) (18.4\%). This seems to suggest that resilience is mainly mediated through the lens of biodiversity and its beneficial effects. The second-ranking principle of opportunities for self-organization (27.4\%) is mostly expressed through the use of verbs of self-organization (e.g. have created, have distributed) (36.6\%), and also through a much lower use of spatiotemporal markers (e.g. local communities, over the last year) (16.6\%), which recall ongoing practices of local resilience. Almost equal importance is given to the principle of evaluating change and uncertainty (26.5\%) with a marked use of negative evaluative adjectives (48.3\%) (e.g. devastating, semi-arid) pointing to the "dramatic expressions of the human impact on planet earth" (S1).

Table 1: Vandana Shiva's SER micro-discourse: quantitative findings.

\begin{tabular}{|c|c|c|c|}
\hline Resilience principles & $\begin{array}{r}\text { Linguistic tokens } \\
(N=219)\end{array}$ & Main linguistic types & $\begin{array}{r}\text { Frequency (\%) } \\
(N=131)\end{array}$ \\
\hline \multirow[t]{2}{*}{ Nurturing diversity } & \multirow[t]{2}{*}{$76(34.7 \%)$} & 'bio' nouns & 27 (35.5\%) \\
\hline & & 'gain' verbs & $14(18.4 \%)$ \\
\hline \multirow{2}{*}{$\begin{array}{l}\text { Opportunities for self- } \\
\text { organization }\end{array}$} & \multirow[t]{2}{*}{$60(27.4 \%)$} & verbs of self-organization & $22(36.6 \%)$ \\
\hline & & spatiotemporal markers & $10(16.6 \%)$ \\
\hline \multirow{2}{*}{$\begin{array}{l}\text { Evaluating change and } \\
\text { uncertainty }\end{array}$} & \multirow[t]{2}{*}{$58(26.5 \%)$} & evaluative adjectives (semi) & $28(48.3 \%)$ \\
\hline & & modal verbs & $11(19.0 \%)$ \\
\hline \multirow[t]{2}{*}{ Knowledge for learning } & \multirow[t]{2}{*}{$25(11.4 \%)$} & 'learning' verbs common \& & $13(52.0 \%)$ \\
\hline & & institutional nouns & $6(24.0 \%)$ \\
\hline
\end{tabular}


Negative evaluation is, however, countered by a more positive one of human change through the use of dynamic modality, which "evaluates the occurrence of events [...] as necessary, important, advisable, possible, desirable, etc. within a circumstantial frame of reference" (Warner 2009: 15). Dynamic modality in the core sense of the "circumstantial possibility" (cf. Palmer 2001: 77) of adaptation and change is particularly reflected in the use of the prototypical dynamic modal can (e.g. organic agriculture can help to mitigate). Dynamic modality is also coherently expressed as "situational dynamic necessity", or "a necessity/inevitability inherent in the situation" (Nuyts 2006: 4), especially by the semi-modal verb need to (e.g. we need to return to the renewable carbon cycle of biodiversity). Hence, change is evaluated in light of the collective actions required to support resilience (e.g. we have started a participatory process for Himalayan communities to engage in the discussion on [...] adaptation and disaster preparedness). Similar actions appear to evoke the principle of knowing for learning despite its low linguistic frequency of occurrence (11.4\%). Verbs connoted with meanings of learning (e.g. reported, defined) are introduced to depict recurring discourse participants represented as common nouns (e.g. women, farmers) and evoke their experiential knowledge (social-ecological memory). International bodies (e.g. Intergovernmental Panel on Climate Change), represented as "institutional" nouns, are also referenced to draw attention to scientific knowledge, thus confirming the will to combine different types of knowledge for learning.

In detail, the findings reveal that resilience meanings are construed to mediate "ecological and social memory" and "novelty" driven by all four enhancing principles. Example (1) refers to the principle of nurturing diversity:

a. In place of synthetic dyes, we have vegetable dyes (S24)

b. In place of the automobile, we have the camel, the horse, the bullock, the donkey, the elephant ... (S25)

c. the renewable carbon embodied in biodiversity offers the solution (S17)

d. And only biodiverse systems provide alternatives that everyone can afford (S30)

The "bio" nouns in bold in (a) and (b) are indicators of ecological alternatives to anthropogenic sources (synthetic dyes, automobile), and of the representation of biodiversity as both social-ecological memory and as a key enabler of renewal or novelty. Furthermore, (c) and (d) both mediate positive change (solution, alternatives) through "gain" verbs (offer, provide), which meaningfully nurture diversity according to the construct of "humans-in-nature", as well as to that of the right to social equity (everyone can afford). 
The positive attitude to change is further conveyed in even more concrete terms when driven by the principle of opportunities for self-organization, as in Example (2):
a. We have created community seed banks of climate resilient crops which have distributed seeds after cyclones, the tsunami, and after draught (S38)
b. Over the last year, Navdany $a^{5}$ Research Foundation teams have worked with local communities in Uttarakhand and Ladakh .... (S86)

In both (a) and (b), the verbs of self-organization (have created, have distributed, have worked) are clear indicators of proactive social resilience planning and collaborative implementation to cope with the aftermath of disturbances (cyclones, tsunami, draught). Social-ecological memory is used to recall these practices within specific spatiotemporal contexts (local communities in Uttarakhand and Ladakh, over the last year).

Moreover, change is evaluated through negative adjectives to reveal factual environmental vulnerability, and thereby to introduce practicable activities which compensate for human-induced loss of resilience, as shown in Example (3):
a. The emission of greenhouse gases comes with... the expansion of intensive agriculture (S60)
b. Biological agriculture... provide[s] a balanced environment... while maintaining an optimum productivity (S64)

It can be noted that the negative evaluative qualifiers (greenhouse, intensive) in (a) are replaced after a few sentences with much more positive ones (biological, balanced, optimum) which point to beneficial ecological alternatives (biological agriculture) and socio-economic ones (optimum productivity).

Furthermore, these positive solutions of renewal also draw mainly on experiential knowledge combined with scientific expertise to develop learning, as in Example (4):
a. For millennia farmers have innovated and evolved varieties with unique properties (S39)
b. According to the Intergovernmental Panel on Climate Change (IPCC), the melting of the Himalayan glaciers goes largely unreported (S141)

As can be seen, knowledge about resilience in (a) and (b) stems from the learning verbs (innovated, evolved, goes unreported), whereby the timeless experiential

5 The movement for biodiversity conservation and organic farming started by Shiva in 1987. 
knowledge (for millennia) of grassroots agents (farmers) is combined with more recent scientific knowledge about the Anthropocene issued by acknowledged international bodies (IPCC).

The results from the micro-analysis of Gore's talk recorded a similar total of linguistic tokens $(N=228)$ related to the resilience-enhancing principles (Table 2).

However, the quantitative findings reveal that resilience is mainly built on the basis of the two principles of evaluating change and uncertainty and knowledge for learning $(76.7 \%)$, whereas the other two strategies are applied to a much lesser extent (23.3\%). Unlike Shiva, Gore focuses more on evaluating change and uncertainty in terms of environmental vulnerability, thus delaying his positive outlook. This is confirmed by the major use of negative qualifiers and action verbs referring to disturbances, as illustrated in Example (5):

a. massive record-breaking downpours (S55); deeper, longer, more pervasive droughts (S78)

b. the same extra heat pulls the soil moisture out of the ground (S74); it dries out the vegetation (S75); the climate-related historic drought destroyed $60 \%$ of the farms ... killed $80 \%$ of the livestock (S79)

As for the principle of knowledge for learning, Gore's talk is featured by verbs of learning referring to the scientific community and to knowledgeable economic entities, while no mention is made of experiential knowledge, as can be seen in Example (6):

(6) a. And one of the things that we learned confirmed what the scientists have long told us (S7); the Brazilian scientists call them [atmospheric rivers] "flying rivers" (S51)

Table 2: Al Gore's SER micro-discourse: quantitative findings.

\begin{tabular}{|c|c|c|c|}
\hline Resilience principles & $\begin{array}{r}\text { Linguistic tokens } \\
(N=228)\end{array}$ & Main linguistic types & $\begin{array}{r}\text { Frequency (\%) } \\
(N=176)\end{array}$ \\
\hline $\begin{array}{l}\text { Evaluating change and } \\
\text { uncertainty }\end{array}$ & 107 (46.9\%) & $\begin{array}{l}\text { evaluative adjectives } \\
\text { action verbs }\end{array}$ & $\begin{array}{l}55(51.4 \%) \\
41(38.3 \%)\end{array}$ \\
\hline Knowledge for learning & $68(29.8 \%)$ & $\begin{array}{l}\text { 'learning' verbs collective } \\
\text { nouns }\end{array}$ & $\begin{array}{l}29(42.6 \%) \\
13(19.1 \%)\end{array}$ \\
\hline $\begin{array}{l}\text { Opportunities for self- } \\
\text { organization }\end{array}$ & $43(18.9 \%)$ & $\begin{array}{l}\text { spatiotemporal markers } \\
\text { verbs of self-organization }\end{array}$ & $\begin{array}{r}22(51.1 \%) \\
9(20.9 \%)\end{array}$ \\
\hline Nurturing diversity & $10(4.4 \%)$ & $\begin{array}{l}\text { 'loss' verbs } \\
\text { 'bio' nouns }\end{array}$ & $\begin{array}{l}5(50.0 \%) \\
2(20.0 \%)\end{array}$ \\
\hline
\end{tabular}


b. ... because the World Economic Forum ... after their annual survey of 750 economists, said the climate crisis is now the number one risk to the global economy (S112); so you get central bankers like Mark Carney, the head of the UK Central Bank, saying the vast majority of the carbon reserves are unburnable (S113)

Furthermore, self-organization as resilience is discursively mediated by referring to the recent actions taken by the countries representing economic powers, as in Example (7):

a. Germany, an industrial powerhouse, one day last December, got $81 \%$ of all its energy from renewable resources, mainly solar and wind (S129)

b. China has already announced that starting next year, they're adopting a nationwide cap-and-trade system ${ }^{6}$ (S188)

Finally, Gore mediates the principle of nurturing diversity to a very limited extent (4.4\%). Unlike Shiva who assigns top discursive priority to this principle through positive "gain" verbs, Gore focuses much more on environmental problems than on pragmatic opportunities through the use of "loss" verbs and related "bio" nouns, as in Example (8):

(8) We're in danger of losing 50\% of all the living species on earth by the end of this century (S92)

It thus seems that more than enhancing resilience building through constructive proposals, Gore tends to evoke the high degree of vulnerability to climate change. This is understood to lead more to raising resilience awareness than to stimulating its actual development, as shown in Example (9):

(9) The answer to the [...] question, 'must we change?' is yes, we have to change (S122).

Gore's use of deontic modality as an attempt to influence the audience's behaviour is here on a par with Shiva's dynamic necessity. The "deontic source" in the rhetorical question is prototypically subjective (the speaker), marked by the modal of obligation must (Huddleston and Pullum 2002: 178), while in the answer it is replaced with objective deontic modality marked by the semi-modal have to for increased public involvement. Yet, the lack of use of the dynamic modality of possibility does not offer the public any concrete collective opportunities for change.

6 A market-based approach to controlling pollution by providing economic incentives for achieving reductions in the emissions of pollutants. 
Besides pushing more explicitly to building resilience, Shiva also raises resilience awareness like Gore. However, this is accomplished in a more critical way, as shown in Example (10):

The biotechnology industry is spreading the misconception that without genetic engineering we will not be able to evolve crops with climate resilience $(\mathrm{S} 50)$.

Beyond the theoretical concept of change in (9), (10) offers a glimpse into the conflictual issues regarding resilient practices.

\subsection{Framing social-ecological resilience discourse}

A total of 167 salient linguistic segments in Shiva's text were found to mirror six main discourse frames (Table 3).

The quantitative findings show that three main frames govern the structure of Shiva's macro-discourse (81.4\%). The top-ranking frame of hope, adaptation and transformation $(38.4 \%)$ is coherently introduced as a new frame to organise meanings of resilience (e.g. feasible solution, hopefully move, for living better) as exemplified in Table 3. Moreover, this frame significantly prevails over the traditional catastrophe one (24.5\%), thus suggesting that disaster events are depicted for the overall purpose of contextualising resilience building. In addition, the justice and equity frame is a clear indicator of the activist's socio-ethical values which appear to be shaped by the issue of the Global North/South divide (contributed the least; suffering the most). More traditional frames (national security, money, polar bear) are used to a much lesser extent (18.6\%), while no instantiations of the scientific uncertainty frame are recorded. It can be argued that this is most probably due to the primary intent to change all audiences and not simply to target those who are unwilling to change (cf. Hulme 2009 above).

It is noteworthy that 217 linguistic segments in Gore's talk also reflected the use of six discourse frames, although these differed from those selected by Shiva in terms of salience (Table 4).

The top three frames deployed by Gore are, in fact, the money, hope, adaptation and transformation, and national security frames (86.7\%). Unlike Shiva, Gore frames his discourse based on the US culture of economy (53.5\%) (e.g. three and a half trillion dollars at risk) much more than organizing it as hope, adaptation and transformation (17.5\%) as Shiva does (38.4\%). Moreover, Gore's national security frame ranks third like Shiva's justice and equity frame, thus further hinting at a cross-cultural semantic difference between the two discourses. The three remaining frames (catastrophe, health, polar bear) occur much less frequently 
Table 3: Shiva's framing of SER discourse.

\begin{tabular}{|c|c|c|}
\hline Frame type & $\begin{array}{l}\text { Linguistic seg- } \\
\text { ments }(N=167)\end{array}$ & Linguistic tokens \\
\hline $\begin{array}{l}\text { 1. Hope, adaptation and } \\
\text { transformation }\end{array}$ & $64(38.4 \%)$ & $\begin{array}{l}\text { - Organic agriculture... seems to be the } \\
\text { feasible solution to ...climate change" (S55) } \\
\text { - This way we will hopefully move to a culture } \\
\text { of caring, a culture of knowledge, a culture of } \\
\text { treading lightly on the earth for living better } \\
\text { (S142) }\end{array}$ \\
\hline 2. Catastrophe & $41(24.5 \%)$ & $\begin{array}{l}\text { Meantime, heavy rainfall which was unknown } \\
\text { in the high altitude desert has become more } \\
\text { frequent, causing flash floods, washing } \\
\text { away homes and fields, trees and livestock } \\
\text { (S123) }\end{array}$ \\
\hline 3. Justice and equity & $31(18.5 \%)$ & $\begin{array}{l}\text { - Tragically, it is those who have contributed } \\
\text { the least to greenhouse gas emissions who } \\
\text { are suffering the most because of climate } \\
\text { chaos (S4) } \\
\text { - This is the direct and cruel face of climate } \\
\text { injustice - the polluters continue to pollute } \\
\text { (S128) }\end{array}$ \\
\hline 4. National security & $12(7.2 \%)$ & $\begin{array}{l}\text { - Climate refugees are already being created in } \\
\text { the Himalaya (S124) } \\
\text { - } \quad \text { The lives of billions are at stake (S143) }\end{array}$ \\
\hline 5. Money & $10(6.0 \%)$ & $\begin{array}{l}\text { - Climate change is basically the residual ex- } \\
\text { ternalities of a fossil-fuel centered economy } \\
\text { (S136) }\end{array}$ \\
\hline 6. Polar bear & $9(5.4 \%)$ & $\begin{array}{l}\text { - The mountains of snow [Himalaya] have also } \\
\text { been called the third pole, since they are the } \\
\text { third largest body of snow on our planet after } \\
\text { the Antarctic and Arctic ( } \mathrm{S} 100)\end{array}$ \\
\hline
\end{tabular}

(13.3\%); no tokens of the scientific uncertainty frame are recorded as in the case of Shiva, thus denoting that Gore's discourse also strives to change all audiences. Despite the limited use of the health frame (3.2\%), it is newly introduced seemingly to amplify the catastrophe frame. In turn, this appears to raise major resilience awareness of environmental disequilibrium and its impact on global sanitary conditions (e.g. microbial diseases from the tropics spread to the higher latitudes).

On the whole, the findings from the frame analysis clearly point to different frame choices across the two narratives, whereby resilience acquires diverse salient meanings. 
Table 4: Al Gore's framing of SER discourse.

\begin{tabular}{|c|c|c|}
\hline Frame type & $\begin{array}{l}\text { Linguistic seg- } \\
\text { ments }(N=217)\end{array}$ & Linguistic tokens \\
\hline 1. Money & $116(53.5 \%)$ & $\begin{array}{l}\text { When you measure it by assets at risk, num- } \\
\text { ber one is Miami: three and a half trillion } \\
\text { dollars at risk (S99) }\end{array}$ \\
\hline $\begin{array}{l}\text { 2. Hope, adaptation and } \\
\text { transformation }\end{array}$ & 38 (17.5\%) & $\begin{array}{l}\text { - We're going to win this. We are going to } \\
\text { prevail (SS137-138) } \\
\text { - We're used to thinking of linear cause and } \\
\text { linear effect - one cause, one effect (S69) }\end{array}$ \\
\hline 3. National security & 34 (15.7\%) & $\begin{array}{l}\text { - The US Defense Department has long warned } \\
\text { of consequences from the climate crisis, } \\
\text { including refugees, food and water shortages } \\
\text { and pandemic disease (S82) }\end{array}$ \\
\hline 4. Catastrophe & $17(7.8 \%)$ & $\begin{array}{l}\text { - These record downpours are creating historic } \\
\text { floods and mudslides (S59) }\end{array}$ \\
\hline 5. Health frame & $7(3.2 \%)$ & $\begin{array}{l}\text { - Right now we're seeing microbial diseases } \\
\text { from the tropics spread to the higher latitudes } \\
\text { (S83) }\end{array}$ \\
\hline 6. Polar bear & $5(2.3 \%)$ & $\begin{array}{l}\text { - } \quad \text { the same storm ... raised temperatures at the } \\
\text { North Pole } 50 \text { degrees Fahrenheit warmer } \\
\text { than normal (S94) }\end{array}$ \\
\hline
\end{tabular}

\subsection{Situating social-ecological resilience cross-culturally}

The results from the comparative analysis reveal that three main constructs of ideology and power underpin each of the sample texts and that these are consistently reflected in the top discourse frames selected. The ideological constructs can be distinguished cross-culturally across the Global North/South divide; the constructs of different types of power are reflected in various linguistic forms as in the examples provided (Table 5).

Owing to the current superpower status of the USA, global economy appears to be the primary ideology underlying resilience discourse in the context of the Global North, where expert authorities (economists) are acknowledged and their authoritative power is legitimated. Bringing this legitimacy to the fore helps persuade the (Western/US) audience of the positive interest in resilience. Conversely, SER thinking is paramount in the context of the Global South, where empowerment is conceived as a global obligation of individual responsibility (we must each make a commitment to change). Empowerment is, instead, conceived as social action in developed countries based on the ideology of the collective will to act (e.g. a lot of people are organizing to insist on this change), which acquires the metaphorical 
Table 5: The cross-cultural constructs of SER ideology and power based on the Global North/ South divide.

The Global North

1. The Economic Cost of the Climate Crisis (money frame)

- Authoritative Power

Economists said the climate crisis is now the number one risk to the global economy (S112)

2. The Collective Will to Act (hope, adaptation and transformation frame)

- Empowerment as Social Action

So, it matters that a lot of people are organizing to insist on this change (S199);

the will to act is itself a renewable resource (S221)

3. Climate Security (national security frame)

- National Power

House Republicans ... had the courage to step out, by telling the truth about the climate crisis (S111)

\section{The Global South}

1. The Importance of SER Thinking (hope, adaptation and transformation frame)

- Empowerment as Individual Responsibility we must each make a commitment to change the way we think, and the way we live so that the earth can flourish (S35)

2. Anthropogenic Vulnerability (catastrophe frame)

- Local Experiential Power

... relying on chemical fertilizers and pesticides for the sake of susceptibility as defined by the West (S61);

Farmers' innovation has stressed on breeding for climate resilience and for conservation of biodiversity (S40)

3. Climate Justice (justice and equity frame)

- Grassroots Power

Through the citizens' actions, we have ...

contributed to the defence of farmers' rights, indigenous knowledge and biodiversity (S47) They [the Ladakhi communities] did not cause the pollution, but they are its victims (S127)

meaning of a renewable resource. By contrast, experiential power is ascribed to local agents in developing countries (e.g. farmers), whereby their renewable practices (e.g. breeding) are in positive contrast with the hegemonic anthropogenic practices imposed by the Global North (chemical fertilizers and pesticides for the sake of susceptibility as defined by the West).

Accordingly, a strong cross-cultural contrast exists between the Southern ideology of climate justice (they did not cause the pollution, but they are its victims), its claimed grassroots power leading to the protection of local rights and knowledge (through the citizens' actions... defence of farmers' rights indigenous knowledge), and the Northern ideology of climate security (telling the truth about the climate crisis) thanks also to national power (House Republicans). On the whole, while both ideologies are embedded with different meanings of hope, adaptation and transformation, divergences affect the notion of power, which is "constantly challenged and as a result reshaped - the power of development does not simply mould the global South in its own Eurocentric image” (Nilsen 2016: 273). 
From a linguistic perspective, a major cross-cultural distinction can be drawn between the persuasive appeals subtly embedded in the two narratives to gain public acceptance of the different ideological viewpoints. On the one hand, the Northern narrative is culturally mediated through the persuasive strategy of appealing to the audience's emotions ( pathos), especially to invoke sympathy from the public. This is particularly accomplished by repeatedly mimicking Obama's well-known campaign chant Yes, we can (change). On the other hand, while the same SER construct of transformation is central to the Southern discourse, Shiva predominantly shapes the meaning of resilience by appealing to the audience's ethical leanings (ethos) based also on her credibility as a renowned environmental expert. Hence, resilience convincingly acquires significance by accounting for change not only within the situation of ecological vulnerability, but also within the social context of inequality and of the imperatives of Global Northern countries.

\section{Discussion and conclusion}

This paper has argued that SER is conceptualized as a function of narrative text and talk, and that multiple linguistic features concur to mediate social-ecological memory and novelty as the key drivers of resilience at different levels of discourse.

At the micro-level, evaluative adjectives were mainly used in both sample texts to evoke the complication of human-induced climate disturbance. Al Gore's talk was, however, found to dwell more on the issue of environmental disequilibrium through the extensive use of negative action verbs, possibly to trigger public reaction for resilience awareness. Gore further delays resolution through the systematic use of "loss verbs", which prioritizes the complication component of his narrative rather than the societal response to climate change. Shiva, instead, merges reaction and resolution early on in her discourse, interweaving mitigation efforts and contributions to adaptation as concrete responses, which also significantly accounts for climate and ecological justice. As a result, focus is placed more on learning from the past for renewal through the use of "learning", "gain" and "self-organization" verbs.

Moreover, Shiva's dynamic modality, as both circumstantial possibility and situational dynamic necessity, is introduced to convey a pragmatic resolution. Gore's use of deontic modality expresses, instead, epistemic necessity, which is "practically inferred from what is known" (Kiefer 1992: 2518), thus soliciting further reaction. Resolution is, in fact, postponed to almost the very end of the talk, when the public is informed about the increasing use of renewable wind and solar energy to generate electricity in the US as an important resilient measure, which is meant to generate emotional relief. 
At the macro-structural level, the framing processes were found to differ remarkably, whereby resilience was attributed distinct cross-cultural meanings under the strong influence of the social context. Accordingly, building resilience in the Global North appears to be more a matter of dealing with the cost of climate change, spreading optimism and ensuring national security (also due to the fear of climate refugees). This raises the question of whether we are living in the Anthropocene or rather in the "Capitalocene" (cf. Moore 2016). By contrast, resilience is framed more pragmatically in the Global South as adaptation and transformation to anticipate future disaster, and to resolve crises emanating from it, also by tackling issues of climate justice and equity. Consistently, the underlying ideologies reveal that power is mediated differently at the socio-discursive level: authoritative and national power is opposed to experiential and grassroots power; empowerment is conceived as social action in the Global North as opposed to the sense of individual responsibility in the Global South.

On the whole, the study has highlighted how text and talk as the media of online environmental activism yield new nuanced SER discourses, and how these are more systematically starting to disseminate the principles of resilience building which merge meanings of climate change as social-ecological memory with those of positive novelty emerging from anthropogenic dynamics. Furthermore, unpacking the frames chosen in the case study has proven helpful in revealing latent cross-cultural meanings of ideology and power embedded in discursive structures, and thereby deeper meanings of resilience.

Analysing SER discourse is not, however, an easy task to accomplish since resilience has still not been adequately conceptualised as a well-defined construct. Accordingly, the conceptual vagueness of SER has led to the rise of multiple public discourses dealing with resilience. These ought to be questioned: whether they disseminate new ways of environmental thinking or merely use the term "resilience" as a flourishing buzzword for recycling the same old concepts (cf. Brown 2016), thus undermining its essential nature of encouraging constructive response to climate disturbance. As SER discourse continues to inspire new forms of climate change communication in the Anthropocene, it deserves further investigation into its evolution, bearing in mind how it intends to engage a wider public in positive change.

\section{References}

Basseler, Michael. 2019. Stories of dangerous life in the post-trauma age. In Astrid Erll \& Roy Sommer (eds.), Narrative in culture, 15-35. Berlin \& Boston: De Gruyter.

Benford, Robert \& David A. Snow. 2000. Framing processes and social movements: An overview and assessment. Annual Review of Sociology 26. 611-639. 
Benson, Melinda. 2015. Reconceptualizing environmental challenges - Is resilience the new narrative? Journal of Environmental and Sustainability Law 21(1). 99-126.

Benson, Melinda \& Robin Craig. 2017. The end of sustainability: Resilience and the future of environmental governance in the Anthropocene. Lawrence, KS: University Press of Kansas.

Berkes, Fikret \& Carl Folke. 1998. Linking social and ecological systems for resilience and sustainability. In Fikret Berkes \& Carl Folke (eds.), Linking social and ecological systems: Management practices and social mechanisms for building resilience, 1-25. Cambridge: Cambridge University Press.

Berkes, Fikret, Johan Colding \& Carl Folke. 2003. Introduction. In Fikret Berkes, Johan Colding \& Carl Folke (eds.), Navigating social-ecological systems, 1-30. Cambridge: Cambridge University Press.

Biggs, Reinette Maja Schluter, Biggs Duan, Erin L. Bohensky, Shauna BurnSilver, Georgina Cundill, Vasilis Dakos, Tim M. Daw, Louisa S. Evans, Karen Kotschy, Anne M. Leitch, Chanda Meek, Allyson Quinlan, Ciara Raudsepp-Hearne, Martin D. Robards, Michael L. Schoon, Lisen Schultz \& Paul C. West. 2012. Toward principles for enhancing the resilience of ecosystem services. Annual Review of Environment and Resources 37. 421-448.

Böhm, Gisela, Hans-Rüdiger Pfister, Andrew Salway \& Kjersti Fløttum. 2019. Remembering and communicating climate change narratives - The influence of world views on selective recollection. Frontiers in Psychology 10. 1026. https://doi.org/10.3389/fpsyg.2019.01026 (accessed 10 August 2018).

Borquez, Roxana, Paulina Aldunce \& Carolina Adler. 2017. Resilience to climate change: From theory to practice through co-production of knowledge in Chile. Sustainability Science 12(1). 163-176.

Brown, Katrina. 2016. Resilience, development and global change. New York: Sage.

Cannon, Terry \& Detlef Müller-Mahn. 2010. Vulnerability, resilience and development discourses in context of climate change. Natural Hazards 55(3). 621-635.

Dalby, Simon. 2013. The geopolitics of climate change. Political Geography 37(1). 38-47.

della Porta, Donatella (ed.). 2014 Methodological practices in social movement research. Oxford: Oxford University Press.

Entman, Robert M. 1993. Framing: Towards clarification of a fractured paradigm. Journal of Communication 43(4). 51-58.

Entman, Robert M., Jörg Matthes \& Pellicano Lynn. 2009. Nature, sources, and effects of news framing. In Karin Wahl-Jorgensen \& Thomas Hanitzsch (eds.), The handbook of journalism studies, 175-190. New York: Routledge.

Fairclough, Norman. 1992. Discourse and social change. Cambridge: Polity Press.

Fleming, Aysha, Vanclay Frank, Claire Hiller \& Stephen Wilson. 2014. Challenging dominant discourses of climate change. Climate Change 127(3-4). 407-418.

Fløttum, Kjersti. 2014. Linguistic mediation of climate change discourse. ASP 65. 7-20.

Fløttum, Kjersti \& Øyvind Gjerstad. 2017. Narratives in climate change discourse. Wiley Interdisciplinary Reviews: Climate Change 8. e429.

Folke, Carl. 2006. Resilience: The emergence of a perspective for social-ecological system analyses. Global Environmental Change 16(3). 253-267.

Folke, Carl. 2016. Resilience (republished). Ecology and Society 21(4). 44.

Folke, Carl, Johan Colding \& Fikret Berkes. 2003. Building resilience and adaptive capacity in social-ecological systems. In Fikret Berkes, Johan Colding \& Carl Folke (eds.), Navigating social-ecological systems, 352-387. Cambridge: Cambridge University Press. 
Folke, Carl, Reinette Biggs, Albert Norström, Belinda Reyers \& Johan Rockström. 2016. Socialecological resilience and biosphere-based sustainability science. Ecology and Society 21(3). 41.

Goffman, Erving. 1974. Frame analysis: An essay on the organization of experience. Cambridge, MA: Harvard University Press.

Gunderson, Lance H. 2000. Ecological resilience - In theory and application. Annual Review of Ecology and Systematics 31. 425-439.

Huddleston, Rodney \& Geoffrey Pullum (eds.). 2002 The Cambridge grammar of the English language. Cambridge: Cambridge University Press.

Hulme, Mike. 2009. Why we disagree about climate change: Understanding controversy, inaction and opportunity. Cambridge: Cambridge University Press.

IPCC. 2007. Climate change 2007: Impacts, adaptation and vulnerability. Contribution of working group II to the fourth assessment report of the intergovernmental Panel on climate change. Cambridge: Cambridge University Press.

Kiefer, Ferenc. 1992. Modality. In Ronald E. Asher (ed.), The encyclopedia of language and linguistics, 2515-2520. Oxford: Pergamon Press.

León, Bienvenido, Maxwell Boykoff, Juhi Huda \& Carmen Rodrigo. 2018. Framing in climate change videos. In Bienvenido León \& Michael Bourk (eds.), Communicating science and technology through online video: Researching a new media phenomenon, 107-119. New York \& London: Routledge.

Linde, Charlotte. 2015. Memory in narrative. In Karen Tracy, Sandel Todd \& Cornelia Ilie (eds.), The international encyclopedia of language and social interaction. https://onlinelibrary.wiley. com/doi/10.1002/9781118611463.wbielsi121 (accessed 2 August 2018).

Lindekilde, Lasse. 2014. Discourse and frame analysis: In-depth analysis of qualitative data in social movement research. In Donatella della Porta (ed.), Methodological practices in social movement research, 195-227. Oxford: Oxford University Press.

McCaughey, Martha \& Michael D. Ayers. 2003. Cyberactivism: Online activism in theory and practice. New York: Routledge.

Moore, Jason W. (ed.). 2016. Anthropocene or capitalocene? Nature, history, and the crisis of capitalism. Oakland, CA: PM Press.

Morris, Brandi S., Polymeros Chrysochou, Jacob Dalgaard Christensen, Jacob L. Orquin, Jorge Barraza, Paul J. Zak \& Panagiotis Mitkidis. 2019. Stories vs. facts: Triggering emotion and action-taking on climate change. Climatic Change 154(1-2). 19-36.

Nilsen, Alf Gunvald. 2016. Power, resistance and development in the global South: Notes towards a critical research Agenda. International Journal of Politics, Culture, and Society 29(3). 269-287.

Nisbet, Matthew C. 2009. Communicating climate change: Why frames matter for public engagement. Environment: Science and Policy for Sustainable Development 51(2). 12-23.

Nuyts, Jan. 2006. Modality: Overview and linguistic issues. In William Frawley, Erin Eschenroeder, Sarah Mills \& Thao Nguyen (eds.), The expression of modality, 1-26. Berlin \& New York: Mouton de Gruyter.

O'Brien, Susie. 2017. Resilience stories: Narratives of adaptation, refusal, and compromise. Resilience: A Journal of the Environmental Humanities 4(2-3). 43-65.

Palmer, Frank R. 2001. Mood and modality. Cambridge: Cambridge University Press.

Penz, Hermine. 2018. 'Global warming' or 'climate change'. In Alwin F. Fill \& Hermine Penz (eds.), The Routledge handbook of ecolinguistics, 277-292. New York \& London: Routledge.

Peterson, Garry D., Graeme S. Cumming \& Stephen R. Carpenter. 2003. Scenario planning: A tool for conservation in an uncertain world. Conservation Biology 17(2). 358-366. 
Plastina, Anna Franca. 2018. Reframing as a persuasive method in public speech: Beyond globalized biodiversity. In Pelclová Jana \& Wei-lun Lu (eds.), Persuasion in public discourse, 127-148. Amsterdam \& Philadelphia: John Benjamins.

Reisigl, Martin \& Ruth Wodak. 2016 [2001]. The discourse historical approach. In Wodak Ruth \& Michael Meyer (eds.), Methods of critical discourse analysis, 3rd edn., 23-61. London: SAGE.

Shanahan, Mike. 2007. Talking about a revolution: Climate change and the media. COP13 briefing and opinion papers. London: International Institute for Environment and Development. https://dlc.dlib.indiana.edu/dlc/bitstream/handle/10535/6263/Talking\%20about\%20a\% 20revolution.pdf?sequence=18isAllowed=y (accessed 14 July 2018).

Steinberg, Marc W. 1998. Tilting the frame: Considerations on collective action framing from a discursive turn. Theory and Society 27(6). 845-872.

Stubbs, Michael. 1997. Whorf's children: Critical comments on critical discourse analysis. In Ann Ryan \& Alison Wray (eds.), Evolving models of language, 100-116. Clevedon: Multilingual Matters.

Van Dijk, Teun A. 1980. Macrostructures: An interdisciplinary study of global structures in discourse, interaction and cognition. Hillsdale, N): Lawrence Erlbaum.

Van Dijk, Teun A. 2018. Socio-cognitive discourse studies. In John Flowerdew \& John E. Richardson (eds.), The Routledge Handbook of critical discourse studies, 26-43. London \& New York: Routledge.

Warner, Anthony R. 2009. English auxiliaries: Structure and history. Cambridge: Cambridge University Press.

Weingart, Peter, Anita Engels \& Petra Pansegray. 2000. Risks of communication: Discourses on climate change in science, politics and the mass media. Public Understanding of Science 9(3). 261-283.

Wertsch, James V. 2008. The narrative organization of collective memory. ETHOS 36(1). 120-135.

\section{Bionote}

\section{Anna Franca Plastina}

Department of Pharmacy, Health and Nutritional Sciences, University of Calabria, Via P. Bucci 87036 Rende, Cosenza, Italy

annafranca.plastina@unical.it

Anna Franca Plastina is Associate Professor of English Language and Linguistics at the University of Calabria, Italy. Her research interests include specialised discourse in computer-mediated communication, corpus-assisted critical discourse analysis, multimodality and psycholinguistics. Her most recent book-length publication is Applied Linguistics and Semantic Web Apps: Cases of Mediated Discursive Practices (2012, Lincom Europa). 